\title{
Prevalence, Treatment, and Control of Depressive Symptoms in the United States: Results from the National Health and Nutrition Examination Survey (NHANES), 2005-2008
}

\author{
Ruth S. Shim, MD, MPH, Peter Baltrus, PhD, Jiali Ye, PhD, and \\ George Rust, $M D, M P H$
}

Background: Depression remains a major public health problem that is most often evaluated and treated in primary care settings. The objective of this study was to examine the prevalence, treatment, and control of depressive symptoms in a national data sample using a common primary care screening tool for depression.

Methods: We analyzed a sample of adults $(n=4836)$ from 2005 to 2008 National Health and Nutrition Examination Survey data. Depressive symptoms were assessed using the Patient Health Questionnaire (PHQ-9) to determine the overall prevalence, rates of treatment, and antidepressant control of mild, moderate, moderately severe, and severe depressive symptoms.

Results: Of the sample, 20.1\% reported significant depressive symptoms (PHQ-9) score, $\geq 5$ ), the majority of whom had mild depressive symptoms (PHQ-9) score, 5-9). Even among individuals with severe depressive symptoms, a large percentage $(36.9 \%)$ received no treatment from a mental health professional or with antidepressant medication. Of those taking antidepressants, $26.4 \%$ reported mild depressive symptoms and $18.8 \%$ had moderate, moderately severe, or severe depressive symptoms.

Conclusions: Despite greater awareness and treatment of depression in primary care settings, the prevalence of depressive symptoms remains high, treatment levels remain low, and control of depressive symptoms are suboptimal. Primary care providers need to continue to focus their efforts on diagnosing and effectively treating this important disease. (J Am Board Fam Med 2011;24: 33-38.)

Keywords: Depression, NHANES, PHQ-9

Depression continues to be major cause of illness and disability throughout the world. ${ }^{1-5}$ The World Health Organization identified depression as the fourth leading cause of total disease burden and the

This article was externally peer reviewed.

Submitted 21 May 2010; revised 1 October 2010; accepted 11 October 2010.

From the Morehouse School of Medicine, National Center for Primary Care, Atlanta, GA.

Funding: This study was funded by the Office of Minority Health grant MPCMP101054-01-00, PI, (GR) and the Atlanta Clinical and Translational Science Institute grant 5 UL 1 RR025008.

Conflict of interest: none declared.

Corresponding author: Ruth Shim, MD, MPH, Morehouse School of Medicine, National Center for Primary Care, 720 Westview Drive, Atlanta, GA 30310 (E-mail: rshim@msm. edu). leading cause of disability worldwide. ${ }^{6}$ In the United States, recent samples estimate a lifetime depression prevalence of $16.2 \%$ and a 12 -month prevalence of $6.6 \%{ }^{7}$

In the past, depression was often underdiagnosed and untreated by physicians in primary care settings. ${ }^{8}$ Studies of elderly patients in primary care settings suggest that complex patients with multiple comorbidities have a higher risk of depression, which is more closely associated with their overall burden of illness than with any one specific disease. ${ }^{9}$ Although rates of treatment are increasing, many people still do not have adequate control of depressive symptoms. ${ }^{7}$ A recent study of a large national sample found that few Americans diagnosed with depression receive guideline-concor- 
dant treatment, with racial/ethnic minority populations receiving even less treatment than non-Hispanic whites. ${ }^{10}$ However, management and treatment of depression in primary care settings is an important issue; previous research has shown that individuals are more likely to seek mental health treatment in primary care settings rather than in specialty mental health clinics. This is particularly true of racial and ethnic minority populations. ${ }^{11}$

The National Health and Nutrition Examination Survey (NHANES) has been used to assess nationwide levels of treatment and control of other chronic diseases ${ }^{12}$ but not depression. According to Cutler et al, ${ }^{13}$ NHANES has become "the principal means to track progress in preventing, treating, and controlling hypertension," guiding national initiatives such as the National High Blood Pressure Education program. In recent versions of the NHANES, use of the Patient Health Questionnaire (PHQ)-9 has allowed for greater accuracy in the diagnoses of mild, moderate, moderately severe, and severe depressive symptoms. ${ }^{14}$ Gonzales et $\mathrm{al}^{10}$ assessed treatment and control rates in a mutliethnic national sample using Collaborative Psychiatric Epidemiology Survey data, but the diagnostic instrument used, the 16-item Quick Inventory of Depressive Symptomology-Self Report is not as commonly used in primary care settings as the PHQ-9. To date, there has been no published study assessing prevalence, treatment, and control using the nationally recognized NHANES dataset and the PHQ-9 instrument, which is widely used to screen for depression and to guide ongoing treatment decisions in primary care and psychiatric settings. Therefore, we examined prevalence of depressive symptoms, rates of treatment, and overall levels of treatment response using the PHQ-9 data in 2005 to 2008 NHANES data.

\section{Methods \\ Design}

The NHANES is designed to assess the health and nutritional status of Americans by combining interviews and physical examinations. ${ }^{15}$ The surveys have been conducted annually by the National Center for Health Statistics since 1999, using a complex multistage sampling design to obtain a representative sample of the civilian, noninstitutionalized population of the United States. The
NHANES oversamples minorities and allows for population estimates using population totals from the Current Population Surveys. To obtain an adequate sample size for the analyses we combined the data from the 2005 to 2006 and 2007 to 2008 NHANES, for a potential total sample size of 11,791 adults aged 18 and older.

\section{Measures}

Depressive symptoms were assessed using the PHQ-9, a 9-item screening tool that asks participants to choose 1 of 4 responses about the frequency of depressive symptoms during the previous 2 weeks. ${ }^{14}$ Those scoring $\geq 10$ were characterized as having moderate, moderately severe, or severe depressive symptoms.

Antidepressant use was defined as taking at least one prescribed antidepressant medication in the past 30 days, as characterized by the Multum Lexicon Drug Database. ${ }^{16}$ During the household interview, survey participants were asked if they had taken a medication in the past month for which they needed a prescription. Those who answered "yes" were asked to show the interviewer the medication containers of all the medications used.

Although the NHANES does not provide details on psychological counseling, we defined counseling and various types of therapy as treatment with a mental health professional, which was measured by the survey question, "During the past 12 months, have you seen or talked to a mental health professional such as a psychologist, psychiatrist, psychiatric nurse, or clinical social worker about your health?"

Because evidenced-based treatment recommendations for prescribing antidepressant medication and/or administering psychotherapy exist for individuals with PHQ-9 scores $>15$, we specifically examined all forms of treatment among respondents that scored $>15$ on the PHQ-9. Evidencebased treatment recommendations for individuals with a PHQ-9 score $<10$ involve a strategy of watchful waiting and reassessment for antidepressant treatment or psychotherapy after 2 months. ${ }^{17}$

\section{Statistical Analysis}

Frequencies, population estimates, standard errors, and $95 \%$ CIs taking into account the complex sampling design and population weights were generated by Proc Crosstabs in SAS-callable SUDAAN version 9 (Research Triangle Institute, Research 
Triangle Park, NC). First, overall prevalence of depressive symptoms and prevalence of the different depressive symptom severity categories were assessed for the entire adult population. Treatment (mental health professional and/or antidepressant) use by depressive symptom severity was then assessed. Prevalence of depressive symptoms, depressive symptom severity, and treatment among different age-sex groups was also examined.

\section{Results}

Among the total sample, 10,283 adults completed the PHQ-9. Based on their scores, 2,399 had depressive symptoms, representing 42,116,283 US adults (21.6\%; 95\% CI, 20.1-23.3), with $14.8 \%$ endorsing mild depressive symptoms, $4.52 \%$ endorsing moderate depressive symptoms, $1.8 \%$ endorsing moderately severe depressive symptoms, and $0.6 \%$ endorsing severe depressive symptoms. Table 1 shows the percentage of the population with depressive symptoms, categorized by age and sex.

Among individuals with moderately severe and severe depressive symptoms (for which guidelines recommend treatment with an antidepressant), $17.0 \%$ (95\% CI, 12.7-22.6) received treatment with an antidepressant only; $17.6 \%$ (95\% CI, $12.0-$ 25.1) had seen a mental health professional only; and $14.8 \%$ (95\% CI, 10.8-19.9) received ideal treatment of antidepressant and treatment by a mental health professional. Even among adults with the most severe depressive symptoms (PHQ-9 score $>20$ ), only $24.8 \%$ (95\% CI, 12.1-44.0) had combined treatment with an antidepressant and a mental health professional, whereas a large percentage $(36.9 \%$; 95\% CI, 24.8-51.0) received no form of treatment either from a mental health professional or with antidepressant medication (see Table 2).

Of the $10.4 \%$ of the US population currently taking antidepressant medications, 54.9\% (95\% CI, 51.2-58.5) were not currently experiencing depressive symptoms. Ongoing mild depressive symptoms continued to be reported by $26.4 \%$ (95\% CI, $23.6-$ 29.4); $11.9 \%$ (95\% CI, 9.5-14.7) endorsed moderate depressive symptoms; $4.9 \%$ (95\% CI, 3.8-6.3) endorsed moderately severe depressive symptoms; and $2.0 \%$ (95\% CI, 1.2-3.3) endorsed severe depressive symptoms.

\section{Discussion}

This study demonstrates the significant gap between optimal depression care and populationbased, real-world measures of care. Given that such a large segment of the US population (roughly 1 in 5 adults, or 42.1 million Americans) screened positive for at least mild depressive symptoms, it may be seen as a major challenge to our nation's health if such a burdensome disease is so frequently undiagnosed, untreated, or undertreated. In many ways it is analogous to the gap between prevalence of elevated blood pressure in the population and levels

Table 1. Population with Mild, Moderate, Moderately Severe, and Severe Depressive Symptoms from Patient Health Questionnaire (PHQ)-9 Scores, by Age and Sex*

\begin{tabular}{|c|c|c|c|c|c|}
\hline & \multicolumn{5}{|c|}{ Depressive Symptoms } \\
\hline & $\begin{array}{c}\text { Mild } \\
(\text { PHQ-9 } \\
\text { score = 5-9) }\end{array}$ & $\begin{array}{c}\text { Moderate } \\
(\text { PHQ-9 } \\
\text { score }=10-14)\end{array}$ & $\begin{array}{c}\text { Moderately Severe } \\
(\text { PHQ-9 } \\
\text { score }=15-19)\end{array}$ & $\begin{array}{c}\text { Severe } \\
(\text { PHQ-9 } \\
\text { score } \geq 20)\end{array}$ & $\begin{array}{c}\text { Total (Any Severity) } \\
\text { (PHQ-9 } \\
\text { score } \geq 5 \text { ) }\end{array}$ \\
\hline \multicolumn{6}{|l|}{ Men } \\
\hline \multicolumn{6}{|l|}{ Age (yr) } \\
\hline $18-54$ & $435(13.31)$ & $142(3.48)$ & $38(1.04)$ & $16(0.39)$ & $631(18.23)$ \\
\hline$\geq 55$ & $208(10.45)$ & $72(3.65)$ & $35(1.44)$ & $6(0.20)$ & $321(15.73)$ \\
\hline All ages & $643(12.52)$ & $214(3.52)$ & $73(1.15)$ & $22(0.34)$ & $952(17.53)$ \\
\hline \multicolumn{6}{|l|}{ Women } \\
\hline \multicolumn{6}{|l|}{ Age (yr) } \\
\hline $18-54$ & $586(16.93)$ & $242(6.24)$ & $103(2.68)$ & $37(0.90)$ & $968(26.75)$ \\
\hline$\geq 55$ & $335(17.06)$ & $89(3.77)$ & $40(1.56)$ & $15(0.44)$ & $479(22.82)$ \\
\hline All ages & $921(16.97)$ & $331(5.47)$ & $143(2.33)$ & $52(0.75)$ & $1447(25.52)$ \\
\hline
\end{tabular}

Values provided as $\mathrm{n}(\%)$.

*Data from the National Health and Nutrition Examination Survey, 2005 to 2008. 


\begin{tabular}{|c|c|c|c|c|}
\hline & \multicolumn{4}{|c|}{ Depressive Symptoms } \\
\hline & $\begin{array}{c}\text { Moderate } \\
(\text { PHQ-9 } \\
\text { score }=10-14)\end{array}$ & $\begin{array}{c}\text { Moderately Severe } \\
\text { (PHQ-9 } \\
\text { score }=15-19)\end{array}$ & $\begin{array}{c}\text { Severe } \\
(\text { PHQ-9 } \\
\text { score } \geq 20)\end{array}$ & $\begin{array}{c}\text { Moderately Severe } \\
\text { and Severe (PHQ-9 } \\
\text { score } \geq 15)\end{array}$ \\
\hline Pharmacologic treatment only & $16.9(13.1-21.5)$ & $17.9(13.0-24.1)$ & $14.4(6.5-28.9)$ & $17.0(12.7-22.6)$ \\
\hline Mental health professional only & $13.3(9.3-18.9)$ & $15.6(9.9-23.7)$ & $23.9(13.9-37.9)$ & $17.6(12.0-25.1)$ \\
\hline $\begin{array}{l}\text { Both pharmacologic treatment and } \\
\text { mental health professional }\end{array}$ & $11.1(7.9-15.5)$ & $11.6(8.1-16.4)$ & $24.8(12.1-44.0)$ & $14.8(10.8-19.9)$ \\
\hline $\begin{array}{l}\text { Neither pharmacologic treatment } \\
\text { nor mental health professional }\end{array}$ & $58.8(51.9-60.6)$ & $54.9(47.3-62.2)$ & $36.9(24.8-51.0)$ & $50.6(43.8-57.4)$ \\
\hline
\end{tabular}

Values provided as \% $(95 \% \mathrm{CI})$.

*Based on Patient Health Questionnaire (PHQ)-9 scores. Data from the National Health and Nutrition Examination Survey, 2005 to 2008 .

of detection, treatment, and "treat-to-target" control of hypertension. Although impressive gains have been made (for example, the proportion of hypertensive patients with at least partially controlled blood pressure, defined by blood pressure $<160 / 95$, rose from $16 \%$ in 1972 to $67 \%$ in $1991) ;{ }^{18}$ still, only $34 \%$ of patients with hypertension have blood pressure completely under control, $25 \%$ are partially treated but uncontrolled, $11 \%$ are taking no medication, and $30 \%$ are unaware that they even have high blood pressure. Eisenberg and Power ${ }^{19}$ used the phrase "voltage drop" to describe the gap between potentially achievable outcomes and those outcomes actually achieved in real-world practice settings, and ultimately in community-based populations.

Primary care clinicians approach patients not as single disease or risk factors, but as whole persons, understanding that depression confers a direct burden of suffering but also complicates the management of various other chronic diseases or risk factors. For example, the epidemiologic evidence for an association between depression and cardiovascular risk is quite strong. ${ }^{20,21}$ Depression prevalence is also higher among individuals with diabetes, ${ }^{22}$ and depression is correlated with poor glycemic control. Depression and metabolic syndrome are correlated as well, and each is an independent predictor of adverse cardiac outcomes. ${ }^{23}$

Beyond considering depression as a risk factor, however, depression is also a disabling disease unto itself, accounting for disability, reduced quality of life, loss of work days, damage to relationships, and even suicide. ${ }^{24,25}$ Although recognition of depression has improved, our data show that more than half of US adults with depressive symptoms are untreated, and 3 of 4 people with severe depressive symptoms are not taking antidepressant medications. Treatment to remission significantly reduces relapse rates in depression; however, almost half of people taking antidepressants have not achieved remission of depressive symptoms. ${ }^{26}$

Formal screening protocols in primary care practices identify many more patients with depressive symptoms than are diagnosed in usual care models. There is an emerging body of evidence to suggest that although screening protocols do detect more cases of depression, they do not by themselves reduce the burden of disease or even improve outcomes. ${ }^{27}$ The US Preventive Services Task Force only recommends screening adults for depression in clinical practices that have systems to ensure accurate diagnosis, effective treatment, and follow-up. However, when coupled with structured approaches to depression care management such as the 3-component model, which integrates nurse care managers and mental health professionals into the primary care practice team, improved outcomes can be achieved. The (Prevention of Suicide in Primary Care Elderly: Collaborative Trial) study showed that medical complexities and comorbid chronic disease common to general internal medicine practices affect treatment outcomes for depression in usual-care settings, but that the impact of comorbidities on depression outcomes can be eliminated with a more intensive approach to depression care. ${ }^{28}$

There are limitations to our study. The use of a national survey provides generalizable data we can apply to the entire noninstitutionalized US population, but it does lack the clinical specificity that might be obtained from direct review of clinical 
records. The PHQ-9 is a self-administered instrument validated for screening, diagnosis, and assessment of the severity of depressive symptoms, with a sensitivity and specificity of $88 \%$ each for major depression. ${ }^{14}$ It is more easily adapted to highvolume primary care settings than instruments such as the Zung or Hamilton Depression Rating Scales.

Using a PHQ-9 score $>5$ to indicate mild, moderate, moderately severe, or severe depressive symptoms, NHANES provides a higher prevalence estimate $(21.6 \%$, or more than 40 million Americans) than other recent surveys. However, combining only moderate, moderately severe, and severe depressive symptoms gives a point prevalence of $6.8 \%$, which is more consistent with other national estimates of a prevalence over a 12 -month period of $6.6 \% .^{7}$ This may indicate that other instruments are not detecting mild depressive symptoms, or that the PHQ-9 threshold of 5 may be overly sensitive but not specific.

It is possible that individuals who screened positive on the NHANES PHQ-9 underreported treatment, either because of recall errors or additional factors (eg, stigma associated with mental illness and its treatment). In addition, individuals who report taking an antidepressant drug may be taking it for conditions other than depressive symptoms and therefore have low PHQ-9 scores. This would lead to an overestimate of the proportion of the population treated to remission, which is already low. We also have no repeated measures or longitudinal tracking to assess the impact of treatment on recently diagnosed individuals, or to estimate the rate of partial response to treatment ( $>50 \%$ reduction in PHQ-9 score).

Furthermore, individuals with bipolar depression may have elevated PHQ-9 scores, but may be prescribed mood stabilizers rather than antidepressants for treatment of depressive symptoms. Although this represents an extremely small number of individuals, it could lead to a slight underestimate of antidepressant treatment rates for individuals with moderately severe or severe depressive symptoms.

\section{Conclusion}

Despite these limitations, these nationally representative data provide a cross-sectional US population estimate of the prevalence of mild, moderate, moderately severe, and severe depressive symp- toms. They also demonstrate that a substantial proportion of persons with symptoms of depression in the United States remain untreated or undertreated. The burden of illness represented by depression care, as well as new evidence suggesting that care and outcomes systematically can be improved, suggest important opportunities for optimizing the treatment of depression in primary care and community health settings as a means of improving overall population health.

\section{References}

1. Ustun T, Ayuso-Mateos J, Chatterji S, Mathers C, Murray C. Global burden of depressive disorders in the year 2000. Br J Psychiatry 2004;184:386-92.

2. Kouzis A, Eaton W. Emotional disability days: prevalence and predictors. Am J Public Health 1994;84: 1304-7.

3. US Department of Health and Human Services. Mental health: a report of the Surgeon General. 1999. Available at: http://www.surgeongeneral.gov/ library/mentalhealth/home.html. Accessed November 13, 2010.

4. US Department of Health and Human Services.18-9. Increase the proportion of adults with mental disorders who receive treatment. Available at: http://www.healthypeople.gov/document/html/ objectives/18-09.htm. Accessed April 10, 2010.

5. Pratt L, Brody D. Depression in the United States household population, 2005-2006. NCHS Data Brief 2008(7):1-8.

6. World Health Organization. The world health report 2002-reducing risks, promoting healthy life. Available at: http://www.who.int/whr/2002/en/. Accessed November 13, 2010.

7. Kessler R, Berglund P, Demler O, et al. The epidemiology of major depressive disorder: results from the National Comorbidity Survey Replication (NCS-R). JAMA 2003;289:3095-105.

8. Goldman L, Nielsen N, Champion H. Awareness, diagnosis, and treatment of depression. J Gen Int Med 1999;14:569-80.

9. Lyness J, Caine E, King D, Cox C, Yoediono Z. Psychiatric disorders in older primary care patients. J Gen Int Med 1999;14:249-54.

10. Gonzalez H, Vega W, Williams D, Tarraf W, West B, Neighbors H. Depression care in the United States: too little for too few. Arch Gen Psychiatry 2010;67:37-46.

11. Snowden L, Pingitore D. Frequency and scope of mental health service delivery to African Americans in primary care. Ment Health Serv Res 2002; 4:123-30.

12. Muntner P, DeSalvo K, Wildman R, Raggi P, He J, Whelton P. Trends in the prevalence, awareness, treatment, and control of cardiovascular disease risk 
factors among noninstitutionalized patients with a history of myocardial infarction and stroke. Am J Epidemiol 2006;163:913-20.

13. Cutler J, Sorlie P, Wolz M, Thom T, Fields L, Roccella E. Trends in hypertension prevalence, awareness, treatment, and control rates in United States adults between 1988-1994 and 1999-2004. Hypertension 2008;52:818-27.

14. Kroenke K, Spitzer R, Williams J. The PHQ-9: validity of a brief depression severity measure. Journal of General Internal Medicine 16(9):606, 2001.

15. US Department of Health and Human Services, Centers for Disease Control and Prevention. National Health and Nutrition Examination Survey, 2007-2008: Overview. Available at: http://www.cdc. gov/nchs/data/nhanes/nhanes_07_08/overviewbrochure_ 0708.pdf. Accessed June 22, 2010.

16. Cerner Multum. Lexicon. Available at: http://www. multum.com/Lexicon.htm. Accessed May 14, 2010.

17. Oxman T, Dietrich A, Williams J Jr, Kroenke K. A three-component model for reengineering systems for the treatment of depression in primary care. Psychosomatics 2002;43:441-50.

18. Burt V, Cutler J, Higgins M, et al. Trends in the prevalence, awareness, treatment, and control of hypertension in the adult US population: data from the health examination surveys, 1960 to 1991. Hypertension 1995;26:60-9.

19. Eisenberg J, Power E. Transforming insurance coverage into quality health care: voltage drops from potential to delivered quality. JAMA 2000;284:2100-7.

20. Fan A, Strine T, Jiles R, Mokdad A. Depression and anxiety associated with cardiovascular disease among persons aged 45 years and older in 38 states of the United States, 2006. Prev Med 2008;46:445-50.

21. Alboni P, Favaron E, Paparella N, Sciammarella M, Pedaci $M$. Is there an association between depression and cardiovascular mortality or sudden death? J Cardiovasc Med (Hagerstown) 2008;9:356-62.

22. Grandy S, Chapman R, Fox K. Quality of life and depression of people living with type 2 diabetes mellitus and those at low and high risk for type 2 diabetes: findings from the Study to Help Improve Early Evaluation and Management of Risk Lactors Leading to Diabetes (SHIELD). Int J Clin Pract 2008;62:562-8.

23. Vaccarino V, McClure C, Johnson B, et al. Depression, the metabolic syndrome and cardiovascular risk. Psychosom Med 2008;70:40-8.

24. Stewart W, Ricci J, Chee E, Hahn S, Morganstein D. Cost of lost productive work time among US workers with depression. JAMA 2003;289:3135-44.

25. Bernal M, Haro J, Bernert S, et al. Risk factors for suicidality in Europe: results from the ESEMED study. J Affect Disord 2007;101(1-3):27-34.

26. Mauskopf J, Simon G, Kalsekar A, Nimsch C, Dunayevich E, Cameron A. Nonresponse, partial response, and failure to achieve remission: humanistic and cost burden in major depressive disorder. Depress Anxiety 2009;26:83-97.

27. Whooley M, Stone B, Soghikian K. Randomized trial of case-finding for depression in elderly primary care patients. J Gen Int Med 2000;15:293-300.

28. Bogner H, Cary M, Bruce $M$, et al. The role of medical comorbidity on outcomes of major depression in primary care: The PROSPECT Study. Am J Geriatr Psychiatry 2005;13:861-8. 